ISSN: $2328-3548$

\title{
Effect of Snake Venom Disintegrin like domain on the Homing of Mesenchymal Stem Cells
}

Research Article

EL-Wahab DA ${ }^{1 *}$, Zaki WS ${ }^{1}$, Habib EK ${ }^{2}$, Basheer AR ${ }^{1}$, Farid TM ${ }^{1,3}$, Hanaa EL.T. Nasser ${ }^{1}$, EL-Asmar MF ${ }^{1}$

${ }^{1}$ Medical Biochemistry Department, Faculty of Medicine, Ain-Shams University, Cairo, Egypt.

${ }^{2}$ Anatomy Department, Faculty of Medicine, Ain-Shams University, Cairo, Egypt.

${ }^{3}$ Clinical Biochemistry Department, Faculty of Medicine, King Abdul-Aziz University, Saudi Arabia.

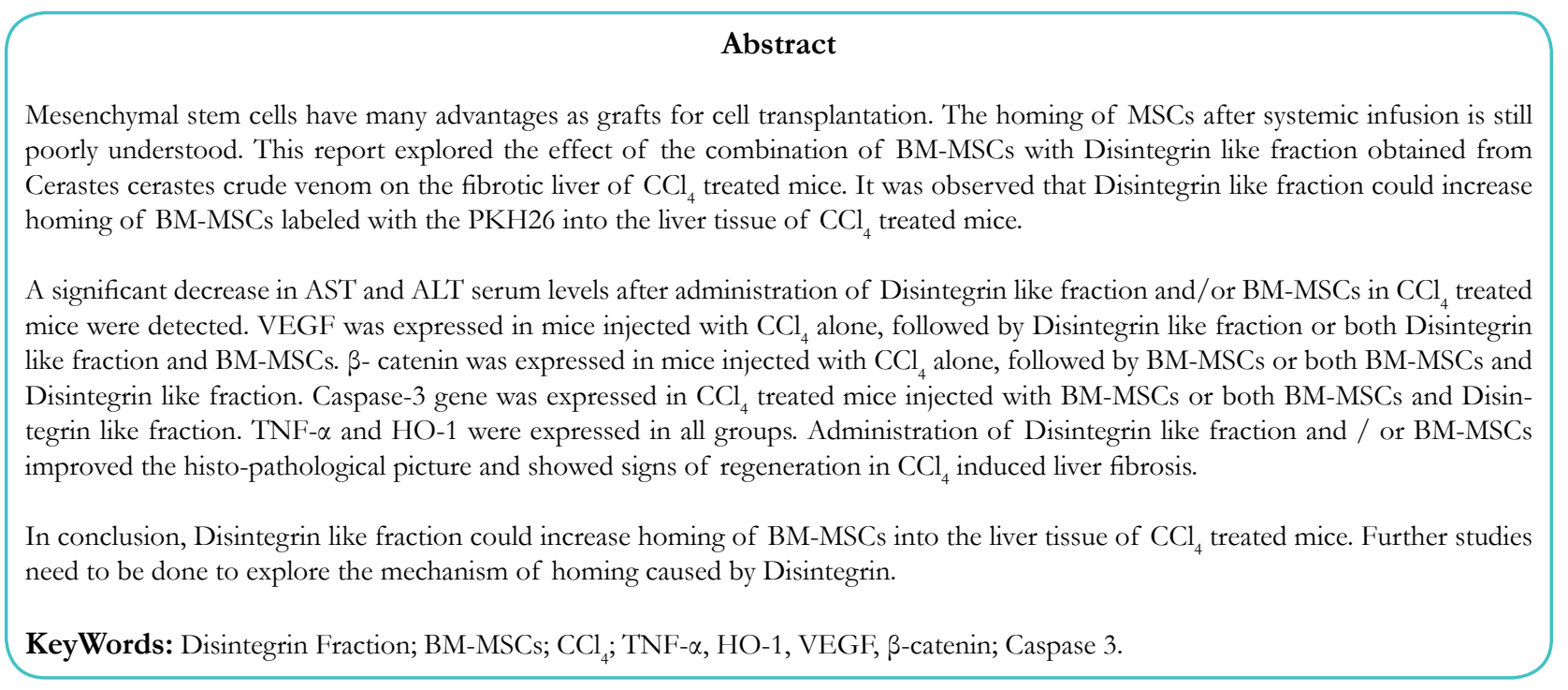

\section{*Corresponding Author:}

Dalia Abd EL-Wahab,

Medical Biochemistry Department, Faculty of Medicine, Ain Shams University, Egypt.

E-mail: dolly.wahab@hotmail.com

Received: May 07, 2014

Accepted: May 24, 2014

Published: May 28, 2014

Citation: EL-Wahab DA, et al. (2014). Effect of Snake Venom Disintegrin like domain on the Homing of Mesenchymal Stem Cells, Int J Stem Cell Res Transplant, 02(03), 69-77. doi: http://dx.doi. org/10.19070/2328-3548-1400012

Copyright: EL-Wahab DA ${ }^{\odot}$ 2014. This is an open-access article distributed under the terms of the Creative Commons Attribution License, which permits unrestricted use, distribution and reproduction in any medium, provided the original author and source are credited.

\section{Introduction}

Stem cell therapy looks attractive for its potential to support tissue regeneration as requiring minimally invasive procedures with few complications [1]. The major problem in the field of cell-based therapies is the delivery of the cells to the site of injury, a process termed homing. Molecular mechanisms underlying stem cells migration and homing into the injured tissues are still poorly understood [2]. Migration and homing of MSCs to the injured tissues require the right combination of signaling molecules from the injured tissue and the corresponding receptors on MSCs [3]. Many potential factors involved in stem cells migration and homing into the injured liver have been characterized, such as the Stromal Cell-
Derived Factor-1[SDF-1]/CXCR4 axis, the proteolytic enzymes matrix metalloproteinase [MMPs], the hepatocytes growth factor $[\mathrm{HGF}]$ and the stem cell factor $[\mathrm{SCF}]$. Many researches focused on approaches that can increase the efficiency of stem cell homing [4].

Disintegrin are small cysteine-rich non-enzymatic proteins that are generated by the proteolytic processing of larger precursor of snake venom metalloproteinase [5]. They have been found to inhibit platelet aggregation, angiogenesis, metastasis and tumor growth [6]. The value of the purified Disintegrin fraction from Cerastes cerastes venom was studied. It was found that it has a hepato-protective effect in white albino mice model treated with $\mathrm{CCl}_{4}$. This hepato-protection role could be through up-regulation of TNF- $\alpha$ and HO-1 genes expression in the liver [7].

Mesenchymal stem cells can be obtained from bone marrow, adipose tissue and umbilical cord blood. It can play a supportive role in organ regeneration processes [8]. Liver stem cell research promises to improve the outcomes of liver diseases and lead to new cell therapies [9]. MSCs have a potential therapeutic effect against liver fibrosis through their effect in minimizing collagen deposition in addition to their capacity to differentiate into hepatocytes in vitro and in vivo [10]. Also, it can mediate liver repair by releasing specific cytokines and growth factors that modulate the activity of tissue-specific cells, suppress local inflammation, and inhibit fibrosis and apoptosis, thereby facilitating liver regeneration $[11,12]$.

TNF- $\alpha$ is a potent pro-inflammatory cytokine exerting pleiotropic effects on various cell types [13]. It participates in liver repair and regeneration following toxic damage [14]. 
HO-1 is an enzyme that catalyzes the rate-limiting step in oxidative heme degradation [15]. HO-1 induction protects from inflammatory liver damage and attenuates $\mathrm{CCl}_{4}$-induced liver fibrosis in rats [16].

The vascular endothelial growth factor [VEGF] is regenerative factor that stimulates endothelial cell proliferation [17]. It is essential for liver regeneration and organ repair [18].

Beta-catenin plays important roles in physiological processes such as liver development, regeneration, and stem cell-assisted regeneration [19].

Caspase-3 plays a central role in the execution-phase of cell apoptosis [20]. Hepatocytes that exposed to $\mathrm{CCl}_{4}$ were significantly up regulated expression of caspase-3 [21].

The present work aimed to study the effect of Disintegrin fraction obtained from Cerastes cerastes snake venom on MSCs homing into injured liver tissue and studying their role in liver regeneration on $\mathrm{CCl}_{4}$ induced liver injury model in white albino.

\section{Materials and Methods}

\section{Preparation of Disintegrin like fraction}

A Disintegrin like fraction was purified from Cerastes cerastes crude snake venom according to [7].

- Gel Filtration Chromatography on Sephadex G 100 fine column followed by ion exchange chromatography on DEAE Sepharose column Effect of A2c fraction on platelet aggregation

- Determination of the purity of the fraction A2c and its molecular weight by Disc SDS-PAGE

- Auto-proteolysis of metalloproteinase/ Disintegrin like fraction by incubation at $37^{\circ} \mathrm{C}$ for 24 hours [7]

- Determination of the auto-proteolysis products and their molecular weights by using Disc SDS-PAGE.

- Re-fractionation of the products of auto-proteolysis [24 hours] by gel filtration chromatography on Sephadex G-50 and identified platelet aggregation inhibitory effect

\section{Labeled BM- derived stem cells with PKH26 source}

Prepared and labeled BM- derived stem cells with PKH26 obtained as injectable preparations from Unit of biochemistry \&molecular biology [UBMB] - Cairo University.

Effects of Disintegrin like fraction, BM- derived stem cells and Carbon Tetra Chloride on Experimental animals
White albino mice of average weight $20-25$ grams. They were allowed water and food ad-libitum and were divided randomly into 5 groups [5-6 mice each]: Group 1 [control]: Injected intra-peritoneally with normal saline as once weekly for 2 weeks in a dose of $0.8 \mathrm{ml} / \mathrm{kg}$ body weight; Group 2: Injected intra-peritoneally with $\mathrm{CCl}_{4}$ dose $0.8 \mathrm{ml} / \mathrm{kg}$ body weight once weekly for 2 successive weeks [22]; Group 3: Injected intra-peritoneally with $\mathrm{CCl}_{4}$ $0.8 \mathrm{ml} / \mathrm{kg}$ once weekly for 2 successive weeks followed one week later by intra-peritoneal injection of Disintegrin fraction $0.3 \mathrm{mg} /$ $\mathrm{kg}$ once weekly for 2 successive weeks [7] ; Group 4: Injected intra-peritoneally with $\mathrm{CCl}_{4} 0.8 \mathrm{ml} / \mathrm{kg}$ once weekly for 2 successive weeks followed one week later by intra-venous injection of labeled BM- derived stem cells at a concentration of $1 \times 10^{6}$ cells [cells were injected intravenously into mice tail vein] once [10] ; Group 5: Injected intra-peritoneally with $\mathrm{CCl}_{4} 0.8 \mathrm{ml} / \mathrm{kg}$ once weekly for 2 successive weeks followed one week later by intravenous injection of labeled BM- derived stem cells $1 \times 10^{6}$ cells [cells were injected intravenously into mice tail vein] and intraperitoneal injection of Disintegrin fraction $0.3 \mathrm{mg} / \mathrm{kg}$.

One week after the last injection, mice were anaesthetized by ether and blood samples were obtained and sacrificed by slaughtering; Livers were dissected from mice. Hepatic specimens were treated for PCR and histo-pathological studies

\section{Biochemical assays}

Alanine aminotransferase [ALT], aspartate aminotransferase [AST] and albumin serum levels were analyzed with a biochemical analyzer [Roche Integra 800, Holliston, United States].

\section{Statistical analysis}

Data were expressed as mean $\pm S D$. Significant differences were determined by using t-test using SPSS 15.0 computer software. Results were considered significant at $\mathrm{p}<0.05$.

\section{PCR detection of certain genes expression}

RNA extraction from liver tissue samples was done [23]. Total RNA was isolated using the GF-1 Total RNA Extraction Protocol provided by [Vivantis technology Company, Malaysia]. RT-PCR was performed using the Viva Two Step RT-PCR Kit [Vivantis Technologies Sdn. Bhd, Malaysia] according to the method of [24]. Specific PCR primers [NCBI, UniSTS] were provided by [Vivantis Technologies Sdn. Bhd, Malaysia]. The expected RT-PCR product size as follows:

TNF- $\alpha$ [180 bp]; HO-1 [206 bp]; VEGF [505 bp]; $\beta$-catenin [397 bp]; Caspase 3 [220 bp].Also, $\beta$-actin [288 bp] was used as

Table 1. Gene primers used for detection

\begin{tabular}{|l|l|l|}
\hline Gene & Sense & Anti-sense \\
\hline TNF- $\alpha$ & 5'TCA TGA ACT TCG GGG TGA TCG 3 & 5'CAG CCT TGT CCC TTG AAG AGA3' \\
\hline HO-1 & 5'AAATAATTCTTTCCCACCCACC3' & 5'CCATGTTGACTGACCACGAC-3' \\
\hline VEGF & 5'CAG GCT GCT GTA ACG ATG AA3' & 5'-CAG GAA TCC CAG AAA CAA CC3' \\
\hline $\boldsymbol{\beta}$-catenin & 5'AAGGAAGCTTCCAGACATGC-3' & 5'AGCTTGCTCTCTTGATTGCC-3' \\
\hline Caspase-3 & 5'TGTCATCTCGCTCTGGTACG3' & 5'AAATGACCCCTTCATCACCA3' \\
\hline Beta actin & 5'AGGTTTTGTCAAAGAAAGGG3' & 5'ACAGTGCTGTCTGGTGGTAC3' \\
\hline
\end{tabular}


a housekeeping gene. All samples were analyzed on $2 \%$ agarose gels. The size of the PCR fragments was estimated using a 1000 base-pair ladder

\section{Examination of liver histo-pathology}

Liver tissue samples were collected and fixed in $20 \%$ formaline then embedded in paraffin and thin transverse sections were prepared and stained with haemtoxylin and eosin stain [25]. Unstained liver tissue sections from the 4th and 5th groups were examined with a fluorescence microscope to detect the BM- derived stem cells stained with PKH26 [11].

\section{Results}

MSCs labeled with PKH26 fluorescent dye detected in the liver tissues obtained from the group which received MSCs only after $\mathrm{CCl}_{4}$ fraction [group 4] [figure 1] and the group which received MSCs and Disintegrin like fraction after $\mathrm{CCl}_{4}$ fraction [group5] [figure 2].

ALT and AST serum levels [U/L] were significantly increased in animals injected with $\mathrm{CCl}_{4}$ alone as compared to that in the control group [p < 0.05]. Albumin serum levels $[\mathrm{g} / \mathrm{dl}]$ were significantly decreased after $\mathrm{CCl}_{4}$ Rsignificantly decreased in animals injected with $\mathrm{CCl}_{4}$ alone as compared to the control group [p < 0.05] as demonstrated in table 2. While, ALT and AST serum levels were significantly lower in animals injected with labeled BMderived stem cells and/ or Disintegrin like fraction after $\mathrm{CCl}_{4}$ as compared to animals injected with $\mathrm{CCl}_{4}$ alone $[p<0.05]$. Regarding Albumin serum levels; there were no significant differences between groups injected with labeled BM- MSCs and/ or Disintegrin like fraction after $\mathrm{CCl}_{4}$ as compared to animals injected with $\mathrm{CCl}_{4}$ alone as demonstrated in table 3 .

TNF- $\alpha$ and HO-1 genes were expressed in liver tissue of all groups except the control group [figures $3 \& 4$, respectively]. Caspase-3 gene was expressed in $\mathrm{CCl}_{4}$ treated mice injected with BMMSCs or both BM-MSCs and Disintegrin fraction [figure 5]. $\beta$ -catenin was expressed in mice injected with $\mathrm{CCl}_{4}$ alone or followed by BM-MSCs or both BM-MSCs and Disintegrin fraction [figure 6]. VEGF was expressed in mice injected with $\mathrm{CCl}_{4}$ alone or followed by Disintegrin fraction or both Disintegrin fraction and BM-MSCs [figure 7].

Histo-pathological examination of liver tissues from control mice
Figure1. MSCs labeled with the PKH26 showed strong red auto-fluorescence after transplantation into mice injected with $\mathbf{B M}$-derived stem cells alone after $\mathbf{C C l}_{4}$ indicating that these cells were seeded into the liver tissue.

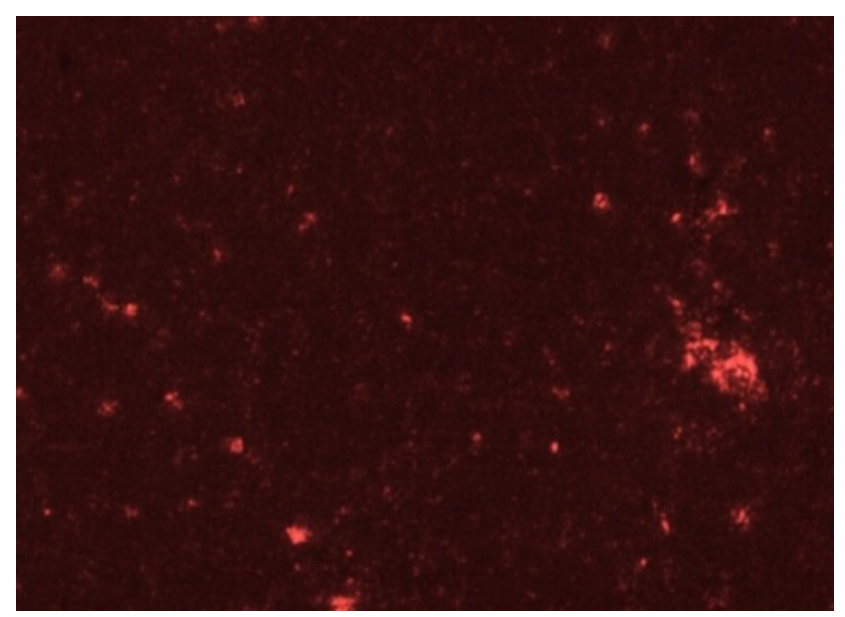

Figure2. MSCs labeled with the PKH26 showed stronger red auto-fluorescence after transplantation into mice injected with both BM- derived stem cells and Disintegrin like fraction after $\mathrm{CCl}_{4}$ indicating that these cells were more seeded into the liver tissue.

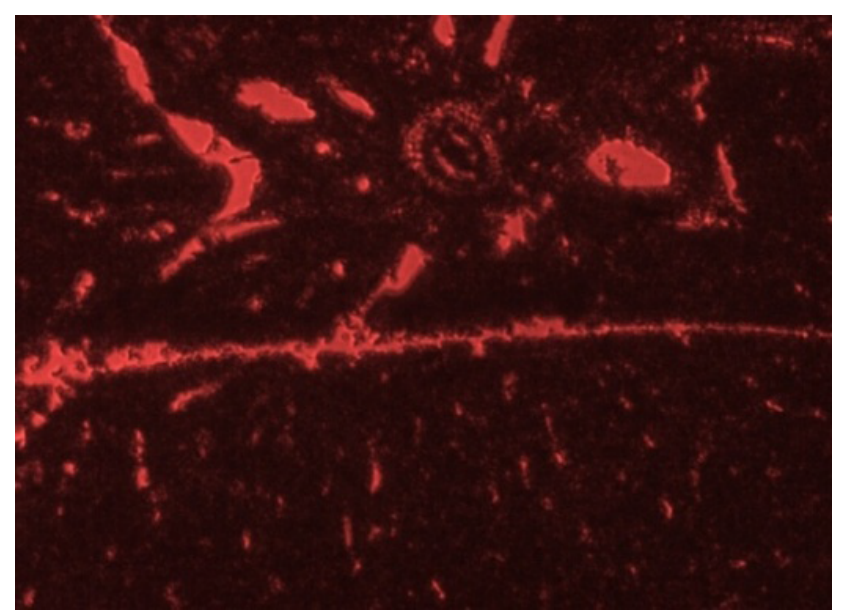

Table 2. Comparison between group 1 and group 2 as regard AST, ALT and albumin serum levels

\begin{tabular}{|l|l|l|l|l|}
\hline Groups & No & ALT [U/L & AST [U/L] & Albumin [g/dl] \\
\hline Group 1 & 5 & $40.8 \pm 8.3$ & $69.0 \pm 7.0$ & $3.8 \pm 0.4$ \\
\hline Group 2 & 5 & $86.2 \pm 7.9^{*}$ & $288.2 \pm 53.5^{*}$ & $2.9 \pm 0.3^{*}$ \\
\hline
\end{tabular}

* Significant at P <0.05; Group 1: control; Group 2: Injected with $\mathrm{CCl}_{4}$

Table 3.Comparison between group 2 and other groups as regard ALT; AST \& Albumin serum levels

\begin{tabular}{|l|l|l|l|l|}
\hline Groups & No & ALT [U/L] & AST [U/L] & Albumin [g/dl] \\
\hline Group 2 & 5 & $86.2 \pm 7.9$ & $288.2 \pm 53.5$ & $2.9 \pm 0.3$ \\
\hline Group 3 & 5 & $64.0 \pm 7.8^{*}$ & $155.6 \pm 52.0^{*}$ & $3.3 \pm 0.5$ \\
\hline Group 4 & 5 & $67.0 \pm 10.0^{*}$ & $156.0 \pm 52.4^{*}$ & $2.9 \pm 0.2$ \\
\hline Group 5 & 5 & $66.0 \pm 7.6^{*}$ & $110.4 \pm 31.4^{*}$ & $3.2 \pm 0.5$ \\
\hline
\end{tabular}

*Significant at $\mathrm{P}<0.05$; Group 2: Injected with $\mathrm{CCl}_{4}$; Group 3: Injected with $\mathrm{CCl}_{4}$ followed by Disintegrin fraction; Group 4: Injected with $\mathrm{CCl}_{4}$ followed by BM- MSCs; Group 5: Injected with $\mathrm{CCl}_{4}$ followed by BM- MSCs and Disintegrin fraction. 
Figure 3. An agarose gel electrophoresis shows PCR product of TNF- $\alpha$ [corresponding to 180 bp]. Lane M: DNA marker. Lane 1, 2, 3, \&4: TNF- $\alpha$ gene was expressed in animals injected with $\mathrm{CCl}_{4}$ and in animals injected with $\mathrm{CCl}_{4}$ followed by Disintegrin fraction and/or BM-MSCs. Lane 5: no expression of TNF- $\alpha$ gene in control group. Lane 6: $\beta$-Actin expression [corresponding to $288 \mathrm{bp}]$

[HK: house - keeping gene].

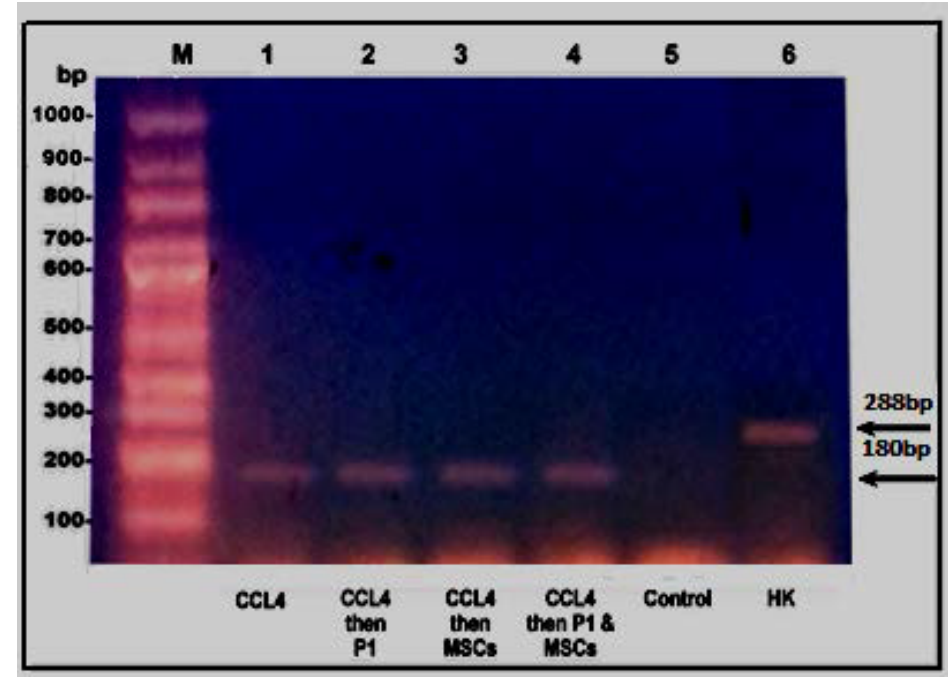

Figure 4. An agarose gel electrophoresis shows PCR product of HO-1 [corresponding to 206bp]. Lane M: DNA marker. Lane 1, 2, 3, \&4: HO-1 gene was expressed in animals injected with $\mathrm{CCl}_{4}$ and in animals injected with $\mathrm{CCl}_{4}$ followed by Disintegrin fraction and/or BM-MSCs. Lane 5: no expression of HO-1 gene in control group. Lane 6: $\beta$-Actin expression [corresponding to $288 \mathrm{bp}$ ]

[HK: house - keeping gene].

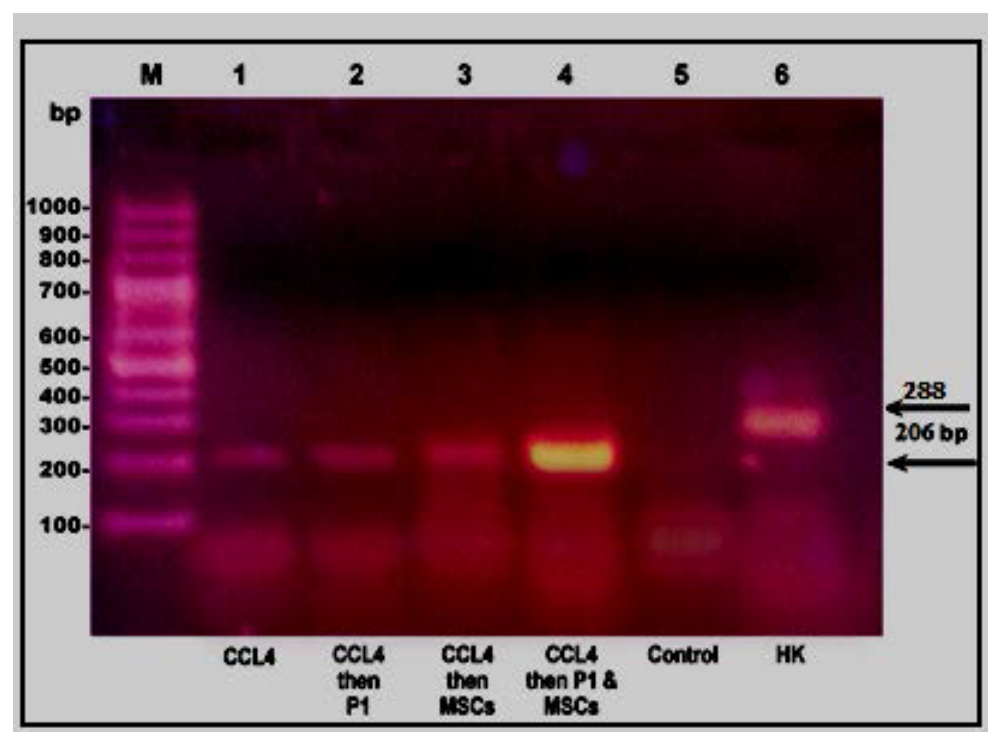

Figure 5. An agarose gel electrophoresis shows PCR product of Caspase 3 [corresponding to 220 bp]. Lane M: DNA marker [100-1000bp]. Lane 1\&2: no expression of Caspase 3 in animals injected with $\mathrm{CCl}_{4}$ or followed by Disintegrin fraction. Lane3\&4: Caspase 3 gene was expressed in animals injected with CC1 $_{4}$ followed by BM-MSCs or both BM-MSCs and Disintegrin fraction. Lane 5: no expression of Caspase 3 in control group. Lane 6: $\beta$-Actin expression [corresponding to 288bp] [HK: house - keeping gene].

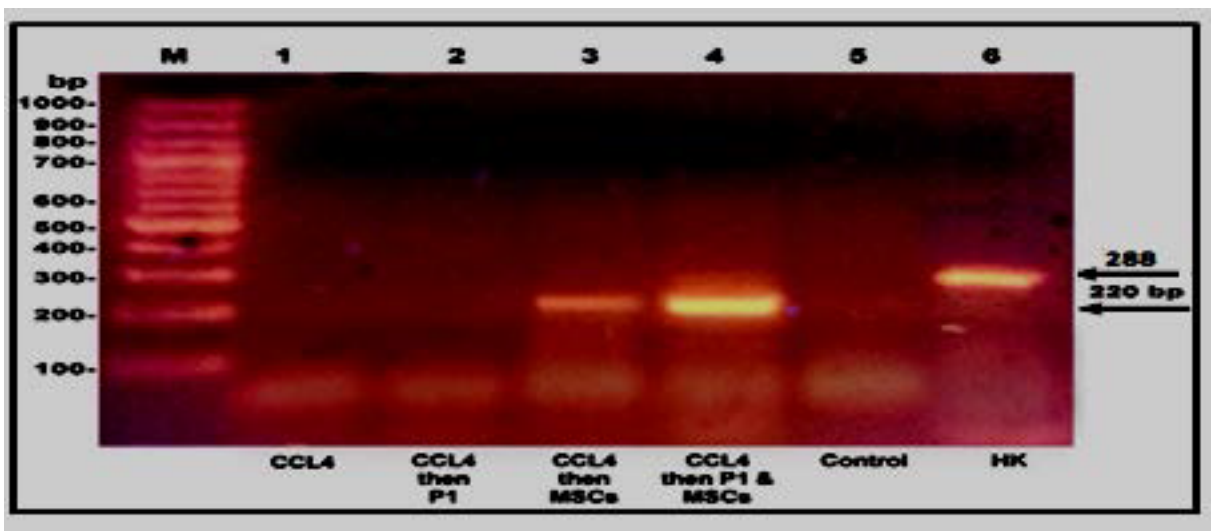


Figure 6. An agarose gel electrophoresis shows PCR product of $\beta$-catenin [corresponding to 397bp]. Lane M: DNA marker [100-1000bp]. Lane 1: $\beta$-catenin was expressed in animals injected with $\mathrm{CCl}_{4}$; Lane2: no expression of $\beta$-catenin in animals injected with $\mathrm{CCl}_{4}$ followed by Disintegrin fraction. Lane3 \&4: $\beta$-catenin was expressed in animals injected with $\mathrm{CCl}_{4}$ followed by BM-MSCs or both BM-MSand Disintegrin fraction. Lane 5: no expression of $\beta$-catenin in control group. Lane 6: $\beta$-Actin expression [corresponding to 288bp] [HK: house - keeping gene]

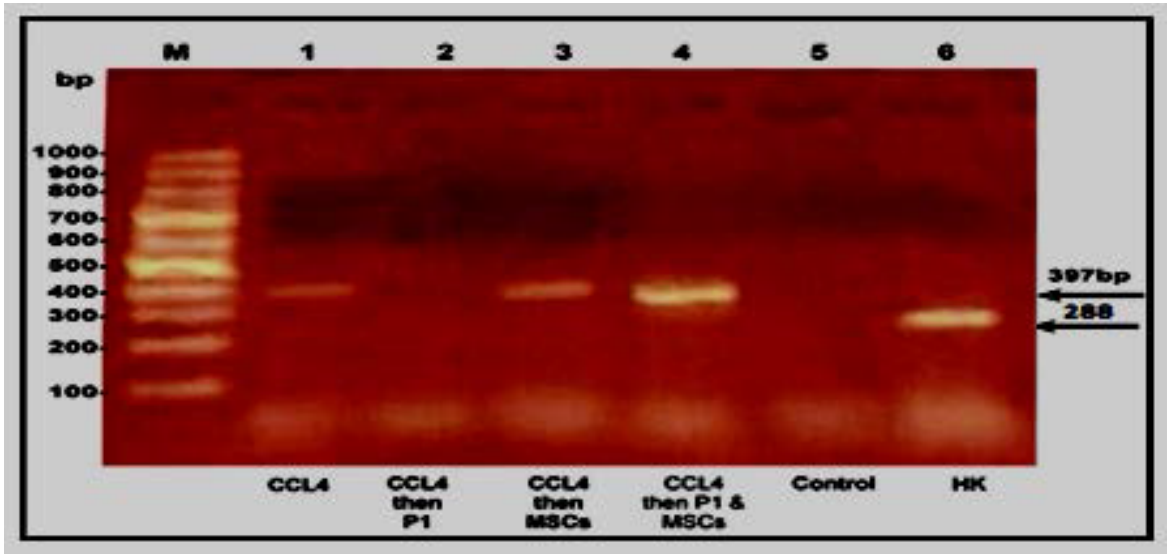

Figure 7. An agarose gel electrophoresis shows PCR product of VEGF [corresponding to 505 bp]. Lane M: DNA marker [100-1000bp]. Lane 1: VEGF gene was expressed in animals injected with CC14; Lane2: VEGF gene was expressed in animals injected with CC14 followed by Disintegrin fraction. Lane3: no expression of VEGF gene in animals injected with CC14 followed by BM-MSCs. Lane 4: VEGF gene was expressed in animals injected with CC14 followed by BM-MSCs and Disintegrin fraction. Lane 5: no expression of VEGF in control group. Lane 6: $\beta$-Actin expression [corresponding to 288bp] [HK: house - keeping gene

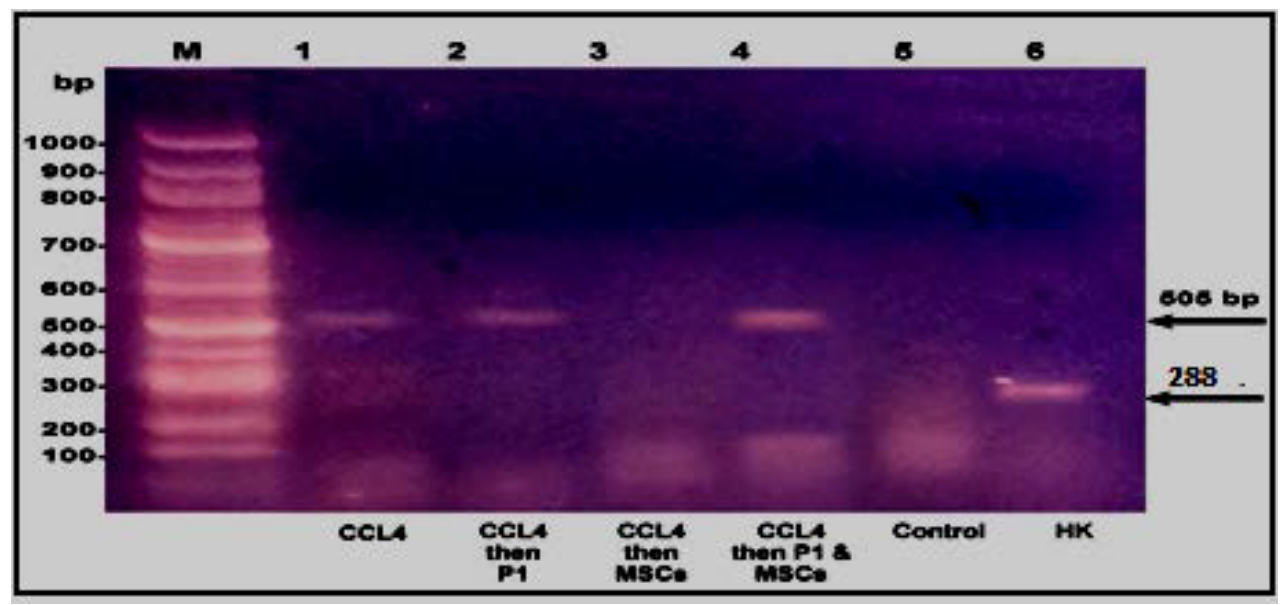

(Group 1) showed cords of normal cells radiating from normal none dilated non congested central vein (CV), normal blood sinusoids (S). While liver tissue samples from animals injected intraperitoneally with $\mathrm{CCl}_{4}$ [Group 2] showed distorted hepatic lobular architecture, dilated central vein surrounded by inflammatory cells, most hepatocytes $[\mathrm{H}]$ are swollen, vacuolated, and ballooned with degenerated nuclei leading to obliteration of some blood sinusoids [S].

But for liver tissue samples from animals injected with $\mathrm{CCl}_{4}$ fraction followed by disntegrin like fraction [group 3] or BM- derived stem cells [group 4] or both [group 5] showed non dilated central vein $[\mathrm{CV}]$, non-obliterated blood sinusoids $[\mathrm{S}]$, few inflammatory cells $[1]$, surrounding normal hepatocytes $[\mathrm{H}]$ with some cells showing signs of regeneration as bi-nucleated cells [B] with dense chromatin [figure8].

\section{Discussion}

MSCs have various actions reported within the liver including trans-differentiation into hepatocytes, stimulation of endogenous hepatocytes proliferation, and suppression of immune mediated rejection [26]. Zhao et al., 2012[8], reported that intravenous injection of MSCs provides the most effective treatment against liver fibrosis induced by $\mathrm{CCl}_{4}$ in mice. In the current study, labeled $\mathrm{BM}$ - derived stem cells were intravenously infused into $\mathrm{CCl}_{4}$ treated mice to study its effect on fibrotic liver in $\mathrm{CCl}_{4}$ treated mice.

Disintegrin are a family of low molecular weight non-enzymatic proteins derived from viper venom [5]. In this study, a Disintegrin fraction with a platelet aggregation inhibitory activity was purified from Cerastes cerastes venom as modified from Zaki et al., (2011) [7]. Many studies reported that Disintegrins inhibit platelet aggregation through integrin aIIb3 and exerts anti-angiogenic activity through integrin avb3 [27].

The homing of MSC after systemic or local infusion has been studied in animal models in a variety of experimental studies [28]. 
Figure 8. Histo-pathological picture of liver tissues in experimental animals stained with Hematoxylin and Eosin [ $\times 400]$. A: Photomicrograph of control group [group1] showing cords of normal liver cells radiating from central vein [CV] with rounded nucleus, some cells are bi-nucleated, blood sinusoids [S] are not obliterated or congested, and few RBCs can be seen within them. B: Photomicrographs of liver tissue from $\mathrm{CCl}_{4}$ mice group [group2] showing degenerative changes in form of vacuolated ballooned and swollen hepatocytes $[\mathrm{H}]$ with foamy cytoplasm, multiple inflammatory cells [I] surrounding dilated and congested central vein [CV] with thickened wall. C,D\& E: Photomicrographs of liver tissue from mice injected with $\mathbf{C C l}_{4}$ mice injected with Disintegrin fraction after $\mathbf{C C l}_{4}$ [group3], mice injected with $\mathbf{B M}-\mathbf{M S C s}_{\text {after }} \mathbf{C C l}_{4}$ [group 4] and mice injected with BM-MSCs and Disintegrin fraction after $\mathbf{C C l}_{4}$ [group5], respectively; showing hepatocytes [H] more or less having normal appearance with its hexagonal shape, some inflammatory cells [I] surrounding congested blood central vein $[\mathrm{CV}]$, hepatocytes show a number of bi-nucleated cells [B] indicating early regeneration.

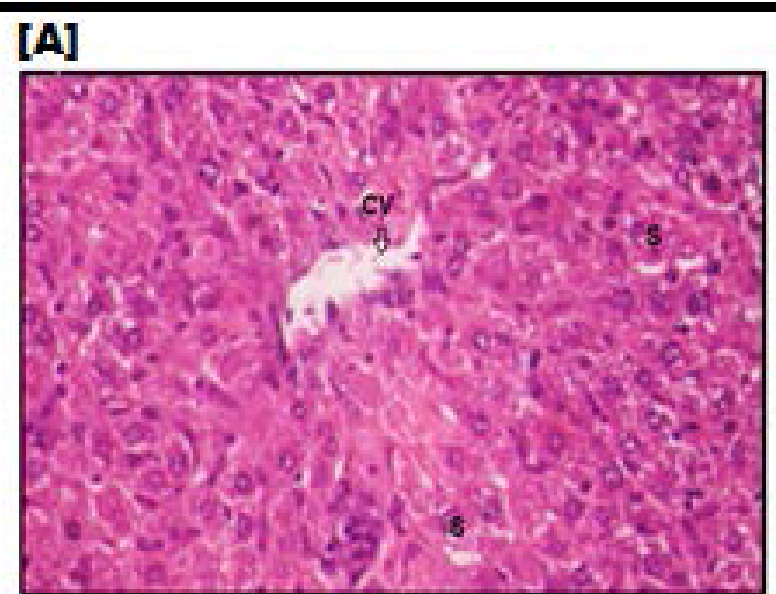

[C]

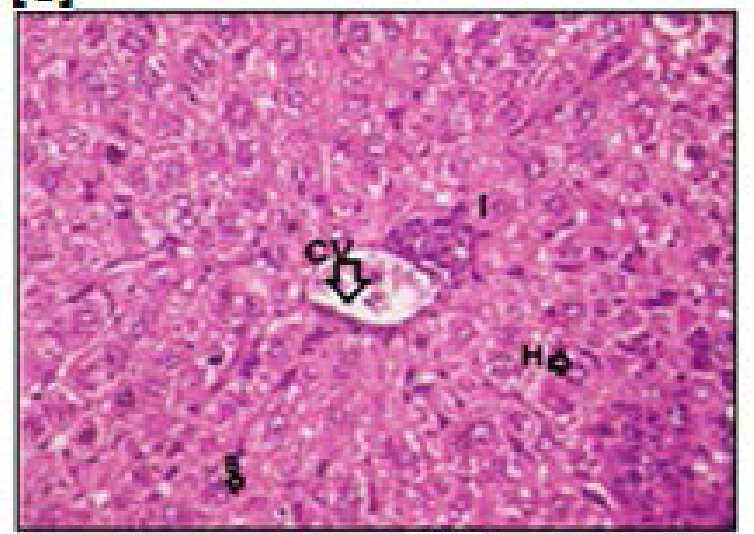

[B]

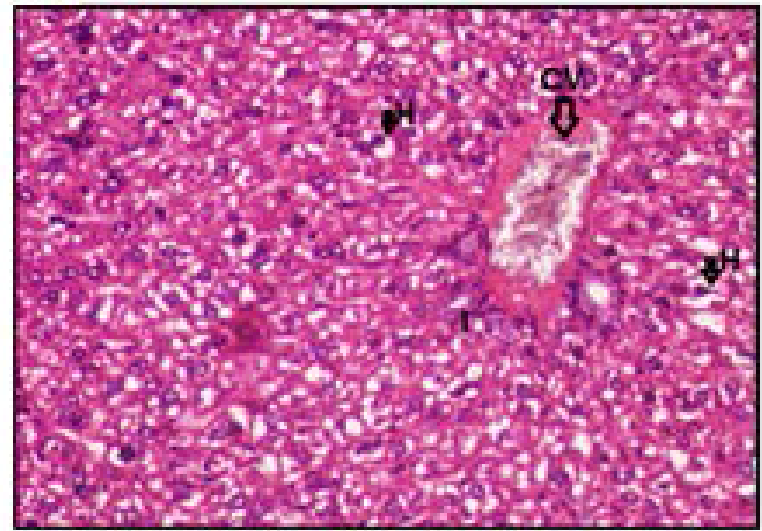

[D]

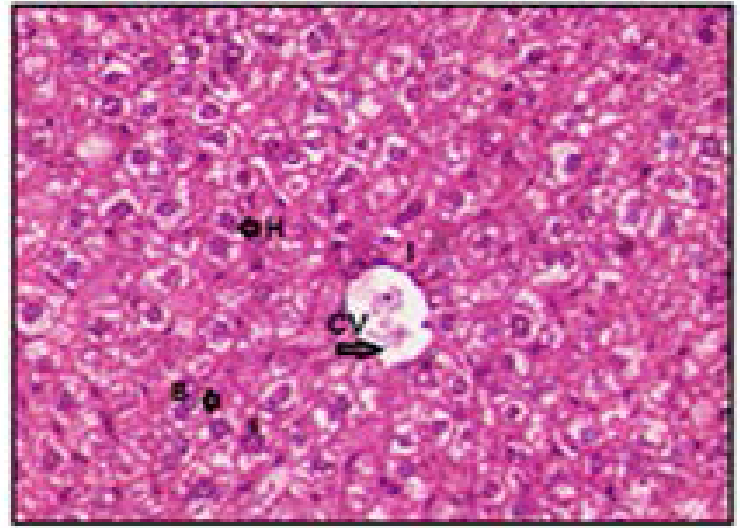

[E]

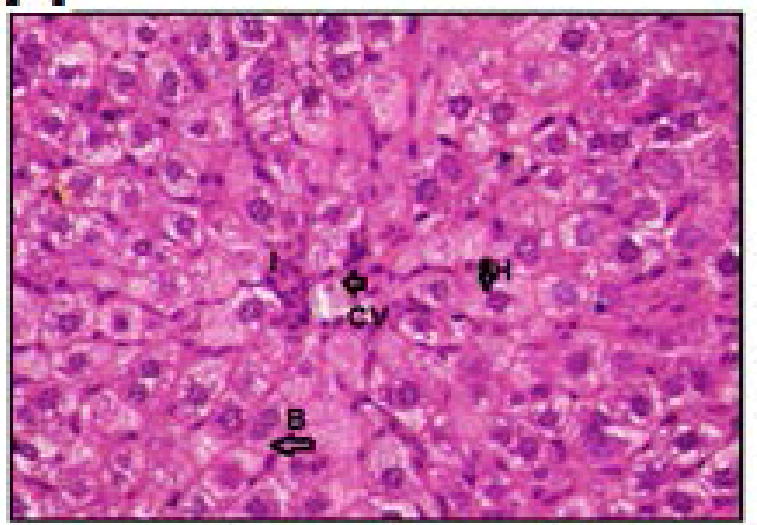


Molecular mechanisms underlying stem cells mobilization and homing into the injured liver are still poorly understood [2].

It was observed that BM- derived stem cells labeled with PKH26 injected with Disintegrin fraction were more seeded into the $\mathrm{CCl}_{4}$ injured liver tissues than when they were injected alone. This finding suggesting that Disintegrin fraction increased the homing of BM-MSCs into the injured liver tissue. In support to this study, Abdel Aziz et al., (2011) [11], detected MSCs labeled with PKH26 fluorescent dye in the liver tissue, confirming that these cells homed into the liver tissue. The current study suggesting that Disintegrin like fraction has a role in increasing BM- derived stem cells homing to liver tissue. Disintegrin fraction may increase the endothelial cell permeability and transmigration of stem cells through the endothelial lining. Also it may interact with integrins involved in endothelial cell-stem cell adhesion. Schulz et al., (2008) [29] demonstrated that ADAM-10 increases permeability and transmigration of $\mathrm{T}$ cells through endothelial cell lining. It was found that transfecting $\mathrm{T}$ cells with ADAM-10 small interfering RNA which blocks ADAM-10 expression decrease in the rate of transmigration of activated T cells. Eto et al., (2000) [30] reported that a Disintegrin domain of ADAM-15 interact with integrins which involved in endothelial cell-leukocyte or endothelial cell -tumor cell adhesion by binding to the classic RGD binding integrins $\alpha 5 \beta 1$ and $\alpha v \beta 3$. Many researches focused on approaches that can increase the efficiency of stem cell homing. Nuttelman et al., (2005) [31] found that arginine-glycine-aspartate [RGD] decorated poly [ethylene glycol] [PEG] based hydrogel promote longterm viability of MSCs in a $3 \mathrm{D}$ environment due to enhanced cell-matrix interaction between RGD moieties of the hydrogel and the encapsulated MSCs promoting proliferation and survival of MSCs.

In the present study, AST and ALT serum levels [U/L] were significantly increased in animals injected intra-peritoneally with $\mathrm{CCl}_{4}$ alone as compared to the control group [p $\left.<0.05\right]$. These goes with Amin and Ghoneim (2009) [32] studies which found that serum AST and ALT levels were significantly increased in the $\mathrm{CCL}_{4}$ induced liver fibrosis group compared to that in the control group as $\mathrm{CCl}_{4}$ induced a severe hepatic damage. While, they were significantly decreased in animals injected with BM- MSCs and/ or Disintegrin like fraction after $\mathrm{CCl}_{4}$ injection as compared to animals injected with $\mathrm{CCl}_{4}$ alone $[p<0.05]$. In agreement, $\mathrm{Li}$ et al., (2013) [33] reported that there is a significant decrease of ALT and AST serum levels after intravenous injection of BM-MSCs for treatment of $\mathrm{CCl}_{4}$ induced liver fibrosis in mice.

Albumin serum levels $[\mathrm{g} / \mathrm{dl}]$ were significantly decreased after $\mathrm{CCl}_{4}$ injection as compared to that in the control group [ $\left.\mathrm{p}<0.05\right]$. In the present work there was no improvement of albumin serum levels after administration of stem cells and /or Disintegrin like fraction after $\mathrm{CCl}_{4}$ injection. In contrast, Zhao et al., (2012) [8] observed improvements of albumin levels after intravenous injection of BM-MSCs for treatment of $\mathrm{CCl}_{4}$ induced liver fibrosis in rats. This could be explained by that albumin serum levels were estimated after 28 days from intravenous injection of Mesenchymal stem cells into rats.

As regards genetic analysis, results showed that TNF- $\alpha$ and HO-1 genes were expressed in the liver tissues of animal groups injected with $\mathrm{CCl}_{4}$ and in animals group injected with Disintegrin fraction and/or BM-MSCs after $\mathrm{CCl}_{4}$ injection. In agreement, Zaki et al., (2011) [7] reported that expression of $\mathrm{TNF}-\alpha$ increased in the liver tissue of experimental animals following exposure to the chemical hepatotoxin carbon tetrachloride $\left[\mathrm{CCl}_{4}\right]$. On the other hand, Minamino et al., (2012) [34] found that recruited macrophages promote liver repair in $\mathrm{CCl}_{4}$ induced liver fibrosis through production of $\mathrm{TNF} \alpha$ and HGF. In contrast, Martino et al., (2012) [14] demonstrated that intra-peritoneal administration of pentoxifylline [PTX], an inhibitor of TNF- $\alpha$ could improve liver regeneration through reduction of liver TNF- $\alpha$ gene expression in rats submitted to partial hepatectomy.

In agreement to this study, Kim et al. (2012) [35] demonstrated a marked increase in HO-1 expression by hepatocytes in the liver of rats treated with $\mathrm{CCl}_{4}$ suggesting that induction of HO-1 following $\mathrm{CCl}_{4}$ treatment has a hepato-protective effect. Nan et al., (2010) [36] explained the hepato-protective role of HO-1 by suppressing hepatocyte apoptosis in mice.

In the current study, VEGF gene was expressed in animal groups injected with $\mathrm{CCl}_{4}$ as VEGF may have a role in liver fibrosis. Yoshiji et al., (2003) [37] reported that it stimulates proliferation of activated hepatic stellate cells [HSC] and significantly increases $\alpha 1$-pro-collagen mRNA by activated hepatic stellate cells leading to ECM production. Also, VEGF gene was expressed in liver tissue of animals injected with Disintegrin like fraction after $\mathrm{CCl}_{4}$ injection and animals injected with both Disintegrin like fraction and labeled BMderived stem cells after $\mathrm{CCl}_{4}$ injection. Kato et al., (2013) [38] reported that VEGF appears to be crucial for liver repair after acetaminophen hepato-toxicity as enhanced VEGF expression promotes liver repair by restoration of the hepatic sinusoids and hepatocytes proliferation mediated by $\mathrm{TNF} \alpha$ and HGF. It was noticed that VEGF wasn't expressed in animals injected with labeled BM- derived stem cells after $\mathrm{CCl}_{4}$ injection. In agreement, Wang et al. (2012) [39] observed that hepatic VEGF mRNA expression was significantly upregulated in $\mathrm{CCl}_{4}$-induced liver fibrosis models and decreased after MSCs transplantation suggesting that suppression of fibrosis by MSCs contributes to VEGF down regulation and modification of liver blood supply. This was against Li et al., (2013)[33] who found that administration of BM- MSCs increased the expression of VEGF in $\mathrm{CCl}_{4}$ induced liver injury so increasing the blood supply to cells and repairing the damaged tissue.

$\beta$-Catenin gene was expressed in animal groups injected with $\mathrm{CCl}_{4}$ and in animal groups injected with BM- MSCs alone or with Disintegrin fraction after $\mathrm{CCl}_{4}$. This goes withR RCheng et al., (2008) [40] who reported that $\beta$ - 10 catenin expression was remarkably increased in culture-activated HSCs during liver fibrosis as activated hepatic stellate cells [HSCs] are the most important source of extracellular matrix proteins. Moreover, Baksh et al., (2007) [41] found that the proliferative effect of $\beta$-catenin on MSCs is achieved by the up-regulation of cyclin D1 and c-Myc, both of which promote growth by driving cell cycle progression. Another role of $\beta$-catenin in MSCs differentiation is that $\mathrm{N}$-cadherin, the key regulator at cell-cell junctions, directly interacts with $\beta$-catenin specifically at the time of Mesenchymal condensation and cell-cell adhesion, which is a critical step in the initiation of differentiation [42].

Moreover, this study detected expression of Caspase-3 gene in animal groups injected with BM- MSCs alone or with Disintegrin like fraction after $\mathrm{CCl}_{4}$ injection. This goes with Xu et al., (2012) [43] who found that poor Mesenchymal stem cell viability in the myocardial injured tissue is due to caspase-dependent apoptosis. This limits the therapeutic effect of transplantation of Mesenchymal stem cells [MSCs] in myocardial infarction. In contrast, Na- 
sir et al (2013) [21] demonstrated that intra-hepatic injection of MSCs 4 weeks after intra-peritoneal injection of $\mathrm{CCl}_{4}$ significantly decrease the expression of apoptotic markers such as caspase-3 so increase the hepatic repair in $\mathrm{CCl}_{4}$ induced liver fibrosis.

Histo-pathological examination of liver tissues from the animals group that received $\mathrm{CCl}_{4}$ alone showed distorted hepatic lobular architecture and necrotic degenerative changes in form of dilated central vein, surrounded by multiple inflammatory cells; most hepatocytes are swollen and vacuolated with degenerated nuclei leading to obliteration of some blood sinusoids. This goes in agreement with studies made by Abdel-Aziz et al., (2005) [22], Zaki et al.,] (2011) [7] and Zhao et al., (2012) [8].

Histo-pathological examination of liver tissues from animals injected with Disintegrin like fraction and / or BM- derived stem cells after $\mathrm{CCl}_{4}$ injection showed mild inflammatory cells with minimal degenerative changes and signs of healing and regeneration in form of normal cellular architecture with bi-nucleated cells, non obliterated non congested central vein and sinusoids. Also, sections showed areas of apparent normal hepatocytes with its hexagonal shape. These goes in agreement with results of studies made about substances induce liver regeneration after $\mathrm{CCl}_{4}$ hepatoxcity $[7,8,22]$. Abdel Aziz et al., (2007) [10] reported a decrease in hepatic fibrosis and improvement of the histo-pathological picture of liver tissues after intravenous injection of bone marrow Mesenchymal cells into $\mathrm{CCl}_{4}$-injured rats.

\section{Conclusion}

The current study results suggest that combination of Disintegrin fraction and Bone marrow derived Mesenchymal stem cells would be useful for liver regeneration of $\mathrm{CCl}_{4}$ induced liver fibrosis in white albino mice. As Disintegrin fraction can increase homing of BM-MSCs into the $\mathrm{CCl}_{4}$ injured liver tissues. Further studies need to be done to find the mechanism of homing caused by Disintegrin.

\section{Acknowledgment}

This work was supported by Ain Shams Faculty of Medicine Grant's office; Grant No: 11

\section{References}

[1]. Lorenzini S, Gitto S, Grandini E, 8TAndreone P and Bernardi M8T.(2008) Stem cells for end stage liver disease: How far have we got? World J Gastroenterol. 14 (29): 4593-4599.

[2]. Muraca M.(2011) Evolving concepts in cell therapy of liver disease and current clinical perspectives. Digestive and Liv.43:180-187.

[3]. Chamberlain G, Fox J, Ashton B and Middleton J.(2007) Concise review mesenchymal stem cells their phenotype, differentiation capacity, immunological features, and potential for homing. Stem Cells. 25: 2739-2749.

[4]. Sohni A and Verfaillie C.M. (2013) Mesenchymal Stem Cells Migration Homing and Tracking. Stem Cells International. http://dx.doi. org/ $10.1155 / 2013 / 130763$

[5]. Takeda S, Takeya H and Iwanaga S.(2012) Snake venom metalloproteinases: Structure, function and relevance to the mammalian ADAM/ADAMTS family proteins. Biochimica et Biophysica Acta. 1824: 164-176.

[6]. Amiryan S.(2011) Antitumor Activity of Disintegrin-Like Components from the Venom of Montivipera raddei. Journal of Cancer Therapy. 2 (5): 752-759.

[7]. Zaki W, Nasser H and El-Asmer M. F. (2011) Natural therapeutic agent derived from snake venom. Lambert academic publishing; Electronic publishing.

[8]. ZhaoW , Li, J, Cao D, et al,(2012) Intravenous injection of mesenchymal stem cells is effective in treating liver fibrosis. World J Gastroenterol. 18 (10): 1048-1058
[9]. Rountree C. B, Mishra L and Willenbring H.(2012) Stem cells in liver diseases and cancer: recent advances on the path to new therapies. Hepatology. 55:298-306.s

[10]. Abdel Aziz M.T, Atta H.M., Mahfouz S. et al. (2007) Therapeutic potential of bone marrow-derived mesenchymal stem cells on experimental liver fibrosis. Clin Biochem. 40:893-899.

[11]. Abdel Aziz M.T, EL Asmar M.F, Atta H.M, et al.(2011) Efficacy of Mesenchymal Stem Cells in Suppression of Hepato-carcinorigenesis in Rats: Possible Role of Wnt Signaling. J Exp Clin Canc Res. 30 (1):49; doi:10.1186/1756-9966-30-49.

[12]. Yuan S, Jiang T, Sun L, et al.(2013) The role of bone marrow mesenchymal stems cells in the treatment of acute liver failure. BioMed Research International . http:// dx. doi. Org / 10. 1155 / 2013 /251846.

[13]. Horiuchi T, MitomaH , Harashima S., et al. (2010) Trans-membrane TNF- $\alpha$ : structure, function and interaction with anti-TNF agents. Rheumatology. 49: 1215-1228.

[14]. Martino R. B, Coelho A. M, Kubrusly M. S and Leitão R. (2012) Pentoxifylline improves liver regeneration through down regulation of TNF- $\alpha$ synthesis and TGF- $\beta 1$ gene expression. World J Gastrointest Surg. 4 (6): 146-151.

[15]. Bessa S. S, Ali E. M, Abd El-Wahab A. E, and Nor El-Din S.A8T (2012) Heme Oxygenase-1 mRNA Expression in Egyptian Patients With Chronic Liver Disease. Hepat Mon. 12(4): 278-285.

[16]. Barikbin R, Neureiter D, Wirth J, et al.(2012) Induction of Heme Oxygenase 1 Prevents Progression of Liver Fibrosis in Mdr2 Knockout Mice. Hepatology. 55: 553-562.

[17]. NamisakiT , Yoshiji H , Noguchi R, et al.(2010) The vascular endothelia growth factor (VEGF) receptor-2 is a major regulator of VEGF-mediated salvage effect in murine acute hepatic failure. J Angiogenes Res. 2 (16). doi: 10. 1186 / 2040 -2384-2-16.

[18]. Bonninghoff R, Schwenke K, Keese M, et al. (2012) Effect of different liver resection methods on liver damage and regeneration factors VEGF and FGF-2 in mice. Can J Surg. 55 (6): 389-393.

[19]. Lade A.(2011) Wnt and beta-catenin in hepatic differentiation: which way does the wnt blow? PhD Thesis University of Pittsburgh.

[20]. Sanii S, Saffar H, Tabriz M, et al.(2012) Expression of Matrix Metalloproteinase-2, but not Caspase-3, Facilitates Distinction between Benign and Malignant Thyroid Follicular Neoplasms . Asian Pacific J Cancer Prev. 13 2175-2178.

[21]. Nasir A , Mohsin S, Khanb M. , et al.( 2013) Mesenchymal stem cells and Interleukin-6 attenuate liver fibrosis in mice. Journal of Translational Medicine. 11 (78). doi: 10. 1186 / 1479-5876-11-78.

[22]. Abdel-Aziz M.T , Aziz M.A, Fouad H.H , et al.(2005) Interferon-alpha gene therapy prevents aflatoxin and carbon tetrachloride promoted hepatic carcinogenesis in rats. Int J Mol Med. 15: 21-26.

[23]. OttoP, KephartD and Bitner R. (1998) Separate isolation of genomic DNA and total RNA from single samples using the SV Total Isolation System. Promega Notes. 69:19-23.

[24]. Al-ShantiN , Saini A and Stewart C. E.(2009) Two-Step versus One-Step RNA-to-CT2-Step and One-Step RNA-to-CT1-Step: Validity, Sensitivity, and Efficiency. Journal of Biomolecular Techniques. 20: 172-179.

[25]. Achliya G.S, Kotagale N.R, Wadodkar S.G and Dorle A.K.(2003) Hepatoprotective activity of Panchagavya Ghrita against carbon tetra chloride induced hepatotoxcity in rats. Indian journal of pharmacology. 35: 308-311.

[26]. Aldridge V, Garg A, Davies N, et al.(2012) Human mesenchymal stem cells are recruited to injured liver in a b1-integrin and cd44 dependent manner. Hepatology. 56(3): 1063-1073.

[27]. Zhu Z, GaoY, Zhu Z, et al.(2009) Structural basis of the autolysis of AaHIV suggests a novel target recognizing model for ADAM/ reprolysin family proteins. Biochem Biophys Res Commun. 386: 159 - 164

[28]. Yagi H, Soto-Gutierrez A, Parekkadan B, et al.(2010) Mesenchymal Stem Cells: Mechanisms of Immuno-modulation and Homing. Cell Transplant. 19 (6): 667-679.

[29]. Schulz B, Pruessmeyer J, Maretzky T, et al.(2008) ADAM10 regulates endothelial permeability and T-cell transmigration by proteolysis of vascular endothelial cadherin. Circ Res. 102:1192 -1201.

[30]. Eto K, Puzon-McLaughlin W, Sheppard D, et al. (2000) RGD-independent binding of integrin $\alpha 9 \beta 1$ to the ADAM-12 and -15 disintegrin domains mediates cell-cell interaction. J Biol Chem. 275: 34922-34930.

[31]. Nuttelman C.R, Tripodi M.C and Anseth K.S.(2005) Synthetic hydrogel niches that promote hMSC viability. Matrix Biol . 24: 208-218.

[32]. Amin A and Ghoneim D. (2009) Zizyphus spina-christi protects against carbon tetrachloride-induced liver fibrosis in rats. Food Chem Toxicol.47: 2111-2119.

[33]. Li Q, Zhou X,Shi Y, et al. (2013) In Vivo Tracking and Comparison of the therapeutic effects of MSCs and HSCs for Liver Injury. PLoSONE. 8 (4): doi: 10.1371 / journal. Pone. 0062363.

[34]. Minamino T, Ito Y., Ohkubo H, et al.(2012) Thromboxane A (2) receptor signaling promotes liver tissue repair after toxic injury through the enhancement of macrophage recruittment. Toxicol Appl Pharmacol. 259: 104114.

[35]. Kim D.W, ChoH.I, Kim K.M, et al. (2012):Isorhamnetin-3-O-galactoside 
Protects against $\mathrm{CCl}_{4} \mathrm{R}$-Induced Hepatic Injury in Mice. Biomol Ther (Seoul), 20(4):406-412. biomolther. 20.4.406.

[36]. Nan Y,Wang R, Zhao S, et al. (2010) Heme oxygenase-1 prevents non-alcoholic steatohepatitis through suppressing hepatocyte apoptosis in mice9T Lipids Health Dis9T. 9(124). doi: 10.1186/1476-511X-9-124.

[37]. YoshijiH , Kuriyama S,Yoshii J, et al. (2003) Vascular endothelial growth factor and receptor interaction is a prerequisite for murine hepatic fibrogenesis. Gut. 52(9): 1347-1354.

[38]. Kato T, Ito $Y$, and Majima M, et al. (2013) VEGF/VEGFR signaling in the liver repair from acetaminophen hepatotoxicity Inflammation and Regeneration . 33: (1): 66-71.

[39]. Wang Y, LianF , Li J,et al. (2012) Adipose derived mesenchymal stem cells transplantation via portal vein improvesmicrocirculation and ameliorates liver fibrosis induced by $\mathrm{CCl}_{4}$ in rats. Journal of Translational Medicine. 10:
(133): doi: 10.1186/1479-5876-10-133.

[40]. Cheng J.H, She H, Han Y.P, et al. (2008) Wnt antagonism inhibits hepatic stellate cell activation and liver fibrosis. Am J Physiol Gastrointest Liver Physiol. 294: 39- 49.

[41]. Baksh D, Boland G.M and Tuan R.S. (2007) Cross-talk between Wnt signaling pathways in human mesenchymal stem cells leads to functional antagonism during osteogenic differentiation. J. Cell. Biochem. 101: 1109-1124.

[42]. Tuan R. S, Boland G and Tuli R. (2003) Adult mesenchymal stem cells and cell-based tissue engineering. Arthritis Res Ther. 5: 32-45.

[43]. Xu J, Qian J, Xie X. et al. (2012) High Density Lipoprotein Protects Mesenchymal Stem Cells from Oxidative Stress-Induced Apoptosis via Activation of the PI3K/Akt Pathway and Suppression of Reactive Oxygen Species. Int. J. Mol. Sci. 13: 17104-17120. 